\title{
Multisite Tumor Sampling Reveals Extensive Heterogeneity of Tumor and Host Immune Response in Ovarian Cancer
}

\author{
SOTIRIOS LAKIS ${ }^{1 *}$, VASSILIKI KOTOULA ${ }^{1,2 *}$, GEORGIA-ANGELIKI KOLIOU ${ }^{3}$, IOANNIS EFSTRATIOU ${ }^{4}$, \\ SOFIA CHRISAFI ${ }^{1}$, ALEXIOS PAPANIKOLAOU ${ }^{5}$, PANTELIS ZEBEKAKIS ${ }^{6}$ and GEORGE FOUNTZILAS ${ }^{1,7,8}$ \\ ${ }^{1}$ Laboratory of Molecular Oncology, Hellenic Foundation for Cancer Research/ \\ Aristotle University of Thessaloniki, Thessaloniki, Greece; \\ ${ }^{2}$ Department of Pathology, School of Health Sciences, Faculty of Medicine, \\ Aristotle University of Thessaloniki, Thessaloniki, Greece; \\ ${ }^{3}$ Section of Biostatistics, Hellenic Cooperative Oncology Group, Athens, Greece; \\ ${ }^{4}$ Department of Pathology, Papageorgiou Hospital, Thessaloniki, Greece; \\ ${ }^{5}$ First Department of Obstetrics and Gynecology, Papageorgiou Hospital, Aristotle University of Thessaloniki, \\ School of Health Sciences, Faculty of Medicine, Thessaloniki, Greece; \\ ${ }^{6}$ First Department of Internal Medicine, AHEPA Hospital, School of Health Sciences, \\ Faculty of Medicine, Aristotle University of Thessaloniki, Thessaloniki, Greece; \\ ${ }^{7}$ Aristotle University of Thessaloniki, Thessaloniki, Greece; \\ ${ }^{8}$ German Oncology Center, Limassol, Cyprus
}

\begin{abstract}
Background/Aim: Ovarian cancer (OVCA) is characterized by genomic/molecular intra-patient heterogeneity (IPH). Tissue histology and morphological features are surrogates of the underlying genomic/molecular contexture. We assessed the morphological IPH of OVCA tumor compartments and of lymphocytic infiltrates in multiple matched samples per patient. Materials and Methods: We examined 294 hematoxylin \& eosin (H\&E) OVCA tumor whole sections from 70 treatmentnaïve patients who had undergone cytoreductive surgery. We assessed morphological subtypes as immunoreactive (IR), solid - proliferative (SD), papilloglandular $(P G)$, and mesenchymal transition (MT); subtype load per patient; stromal tumorinfiltrating lymphocyte (sTIL) density as average per sample; and, as maximal sTIL values (max-TILs) among all samples per patient, ovaries and implants. Results: Among all 294 tumor sections, the most frequent primary morphological subtype was $P G(n=150,51.0 \%)$, followed by $M T(71,24.1 \%), S D(48$,
\end{abstract}

This article is freely accessible online.

*These Authors contributed equally to this study.

Correspondence to: Sotirios Lakis, MD, Laboratory of Molecular Oncology, Hellenic Foundation for Cancer Research/Aristotle University of Thessaloniki, University Campus, Blg. 8, 54124 Thessaloniki, Greece. Tel/Fax: +30 2310 999040; e-mail: slakis@auth.gr

Key Words: Mesenchymal subtype, immunoreactive subtype, solid subtype, TILs, tumor stroma, proliferation.
$16.3 \%)$ and $I R(15,5.1 \%)$. Subtype combinations were observed in 67/294 sections (22.8\%) and IPH in 48/70 patients (68.6\%). $P G$ prevailed in ovaries $(p<0.001), S D$ and $M T$ in implants $(p=0.023$ and $p<0.001$, respectively). sTILs were higher in $S D$ compared to non-SD $(p=0.019)$ and lower in $P G$, respectively $(p<0.001)$. sTIL density was higher in implants than in ovaries $(p<0.001)$. Higher max-TILs were associated with stage IV disease $(p=0.043)$, upper abdominal dissemination $(p=0.024)$, endometrioid histology $(p=0.013)$, and grade 3 tumors $(p=0.021)$. Favorable prognosticators were higher max-TILs per patient (PFS, OS) and higher SD-load (PFS). Conclusion: Clinically relevant morphological and host immune-response IPH appear to be the norm in OVCA. This may complicate efforts to decipher sensitivity of the tumor to certain treatment modalities from a single pre-operative biopsy.

Pathologic diagnosis of epithelial ovarian cancer (OVCA) takes into account the different origin, pathogenesis and prognosis of major histologic types with minimal or no consideration of the biological characteristics of the tumors $(1,2)$. OVCA histological types are considered for patient management, while genetic counselling and tumor genotyping with particular emphasis on BRCA1/2, homologous recombination and mismatch repair deficiency were only recently recommended for maintenance treatment options $(3,4)$. OVCA is not among the first 10 causes of cancer-related morbidity but it ranks fifth with respect to cancer-related mortality $(5,6)$, necessitating improvement at all steps of patient management and a deeper understanding of tumor biology. 
Molecular/genomic tumor and host related characteristics have dominated OVCA research for years. OVCA are classified into four molecular subtypes; namely as immunoreactive, differentiated, proliferative and mesenchymal (7), which partially overlap $(8,9)$ with the earlier described molecular classification of OVCA (10). Although most studies agree that the mesenchymal subtype confers worse prognosis, reproducibility of this classification $(11,12)$ and of its clinical relevance $(12$, 13) seems to depend on sample purity and on the employed classifiers/ gene sets; as well as on the intrinsic molecular heterogeneity of $\operatorname{OVCA}(7,14)$.

The high mortality of OVCA is partly due to late diagnosis (6). At this advanced stage, clonal evolution and expansion have occurred $(15,16)$, which explains the widely reported intra-tumoral/intra-patient heterogeneity at the genomic (1620 ) and transcriptomic level $(7,9)$ with only an estimated $25 \%$ of potentially "pure" molecular subtypes at diagnosis (12). Intra-patient OVCA heterogeneity has been demonstrated at different levels, including tumor microenvironment and immune cell infiltrates within the same site and among disease dissemination sites $(9,21,22)$. The challenge remains to use the above knowledge on the biological subtypes and heterogeneity in a clinically meaningful way (12).

To this aim, morphological surrogates for the molecular subtypes have been introduced, taking into account tissue architectural patterns, stromal contexture and amount of immune infiltrates (23). In this classification, patients with the morphological mesenchymal subtype had the worse prognosis.

In the present study, we interrogated histological patterns in multiple matched primary and metastatic tumor sites in a series of patients with OVCA who underwent primary cytoreductive surgery and were subsequently treated with platinum-based chemotherapy. We used routine hematoxylin and eosin (H\&E) sections and analyzed histological patterns along with available biological parameters, including previously published genotypes for the cohort (20). Given the extensive molecular heterogeneity of OVCA, we hypothesized that the entire surgical specimen may contain diverse histological patterns of the tumor and its microenvironment and that this may affect the clinical outcome.

\section{Materials and Methods}

Patients and tissues. We retrospectively analyzed biological material from 70 OVCA patients who were diagnosed over a period of 10 years (2004-2013), underwent cytoreductive surgery, and received standard paclitaxel-carboplatin chemotherapy at the Department of Medical Oncology, Papageorgiou Hospital, Faculty of Medicine, Aristotle University of Thessaloniki (AUTH), Thessaloniki, Greece. Following signed informed consent and study approval by the AUTH Bioethics Committee (Approval \#79/10.6.2014) and by the Papageorgiou Hospital Institutional Review Board (193rd Meeting decision, 15.1.2014), formalin-fixed paraffin-embedded (FFPE) tissue blocks from the resected tumors were obtained from the Pathology
Department. Detailed patient demographic, clinicopathological, treatment and outcome data were retrieved from the Hellenic Cooperative Oncology Group (HeCOG) data office. Germline status and tumor genotyping results for the same patient cohort were previously reported (20). We assessed 294 unique H\&E whole sections from an equivalent number of FFPE blocks containing tumor tissue for pathological and biological characteristics at the Laboratory of Molecular Oncology (MOL; Hellenic Foundation for Cancer Research/HeCOG/AUTH).

Histological tumor tissue assessment. One representative H\&E slide from each block was reviewed by S.L., blinded to patient characteristics. Tumors were classified into four morphological subtypes, immunoreactive (IR), solid - proliferative (SD), papilloglandular (PG), and mesenchymal transition (MT), using a modified version of the previously described algorithm (23). IR tumors displayed smooth borders and extensive lymphocytic infiltration covering $>60 \%$ of the intra- and peri-tumoral stroma. SD tumors were characterized by marked nuclear anaplasia and extensive (solid) epithelial outgrowth with little amount of stroma. PG consisted of well-defined papillary or glandular architecture. Finally, MT were characterized by destructive invasion consisting of compressed or angulated papillary/glandular or trabecular epithelial nests embedded in prominent desmoplastic stroma, with occasional foci of single cell invasion or spindle-cell forms. All observed subtypes were recorded per whole tumor section, provided that each subtype occupied $\geq 10 \%$ of the tumor area.

Stromal tumor-infiltrating lymphocytes (sTIL density or sTILs) were assessed based on Salgado et al. (24) as the percentage of the intra- and peri-tumoral stroma area occupied by small, round mononuclear cells including plasma cells. The slides were initially screened at low magnification to select representative areas both at the tumor core and at the invasive margin, which were subsequently evaluated in more detail at $200 \times / 400 \times$ magnification. An average TIL estimate across the entire tumor area was reached by assessing 2-10 high power fields.

Description of the examined histological characteristics is provided in representative examples of morphological subtypes and sTIL density in Figure 1A-E. Areas with remarkable stromal lymphocytic infiltration but with an irregular tumor-host interface were assigned into MT, PG or SD, depending on the stroma/epithelial ratio and the configuration of the epithelial nests.

Biological parameters. Immunohistochemistry for Ki67 was applied with the MIB1 antibody on tissue microarray sections, containing $2 \times 1.5 \mathrm{~mm}$ cores from each tumor tissue block. Ki67 was evaluated in tumor cells (average percentage of positive nuclei in the two cores per sample) and in stromal cells (maximal percentage between the two cores). Data for genes with pathogenic mutations per sample, as well as available germline data were retrieved from the previously published dataset (20).

Statistical analysis. The basic morpho - biological parameters evaluated in this study and their distribution with respect to tumor sample origin (ovaries/intra-abdominal implants) are shown in Figure 1F. Among the examined 294 tumor sections, 37.1\% derived from ovaries and $62.9 \%$ were implants. One to eight samples were available for the examined patients, 4.2 on average. Study variables were (a) analyzed for individual samples and for matched samples per patient; (b) evaluated per patient for all matched samples (case) and separately in the ovaries and implants. 

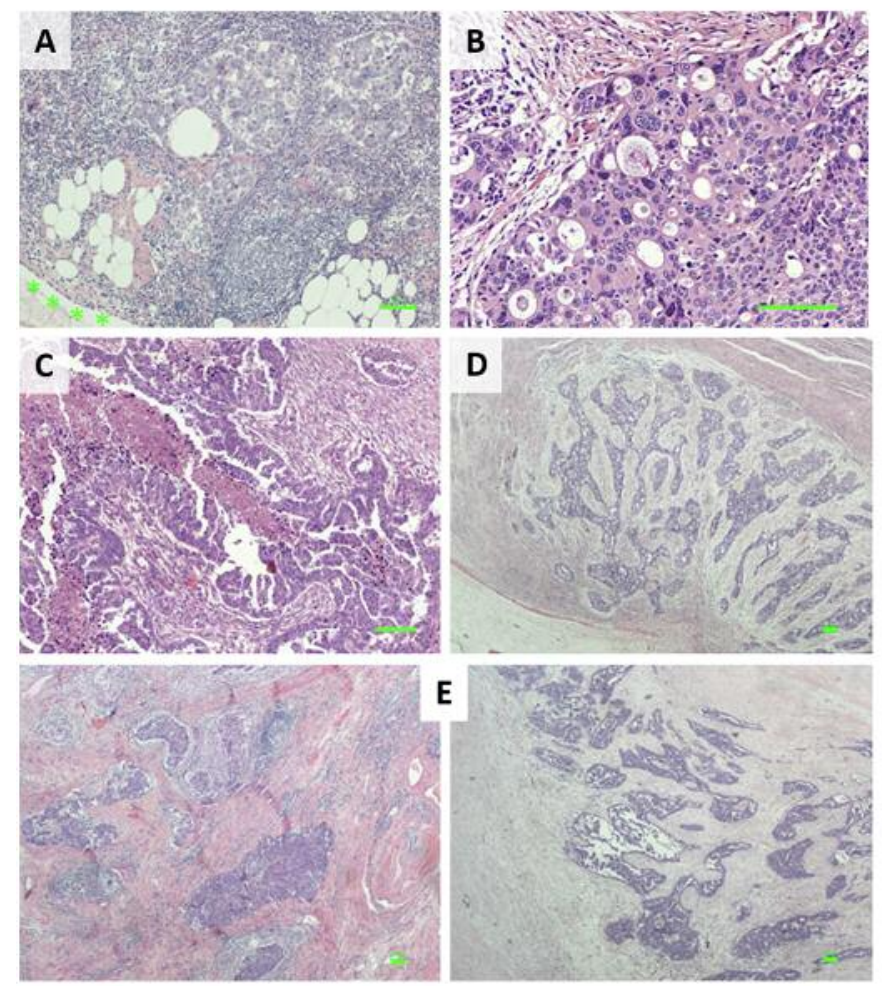

$\mathbf{F}$

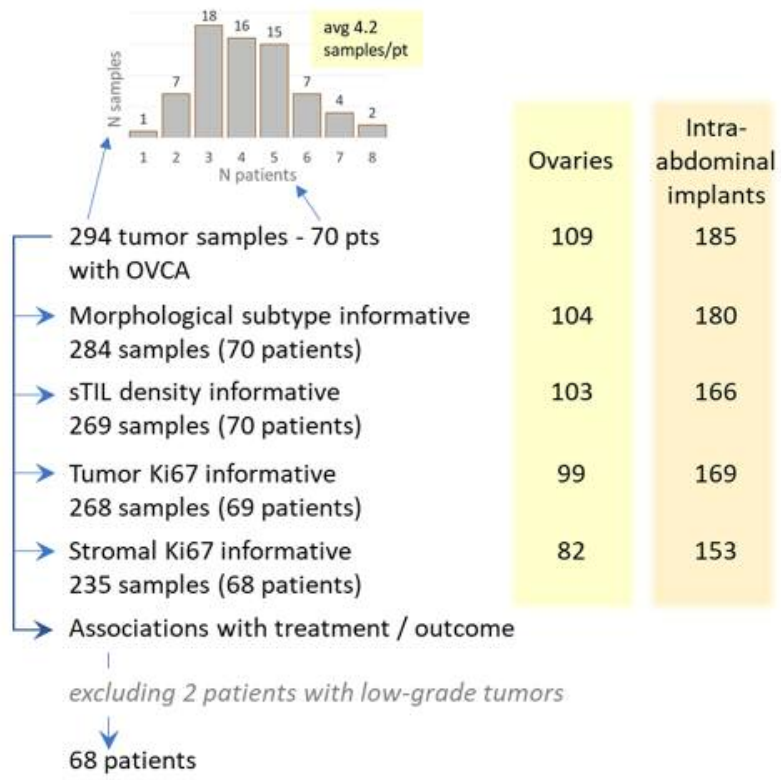

Figure 1. Morpho - biological parameters assessed in this study. A-E. Examples of morphological subtype patterns on whole sections. A: Immunoreactive subtype in the omentum, with $80 \%$ stromal tumor-infiltrating lymphocytes (sTILs) and a smooth border (green asterisks); these tumors were reminiscent of the medullary histological subtype of breast cancer B: Solid subtype) in a peritoneal implant, with marked nuclear anaplasia and $20 \%$ sTILs C: Papilloglandular subtype in a peritoneal implant, with comedo-like necrosis and $<1 \%$ TIL area in the surrounding stroma. D: Mesenchymal transition subtype in the, ovary, with 20\% sTILs, E: ovarian tumor with the immunoreactive subtype (left) and mesenchymal transition subtype (right). All scale bars (green) at $100 \mu \mathrm{m}$. F. Outline of studied parameters. The distribution of examined tumors per patient is shown in the bar chart on the top; the distribution of examined tumor samples with respect to ovarian or implant origin for each parameter is shown in the columns on the right.

The presence of the morphological subtypes was assessed on each section separately as a categorical variable (yes/no); percentage (load) of the occupied area within the same section (continuous variable); average load among matched samples from the same case (subtype load, continuous); and high/low load dichotomized at the median value (categorical). Intra-tissue heterogeneity was considered if one subtype was represented in $\geq 10 \%$ of the total tumor area on the whole section. Intra-patient heterogeneity reflected the presence of multiple subtypes among samples of the same patient.

sTILs were assessed per section and per morphological subtype in sections with co-existing subtypes. Both maximal and average values were calculated in heterogeneous cases separately for ovaries and implants and at the patient level. The Euclidean distance of sample sTIL values was also calculated per case in order to approach heterogeneity of sTILs among tumor tissues from matched multiple sites.

All numerical variables were analyzed as continuous but were also dichotomized at the median value (high/low) for the presentation of outcome estimates. Biological significance was considered for Spearman's correlation coefficients (rho values) $>0.5$. Statistical significance was set at 5\%. For this study, follow-up was updated in December 2019. Progression-free (PFS) and overall (OS) survival were considered from the date of treatment initiation until event (progression or death) or last contact. Probability of survival was assessed with the Kaplan-Meier method and the log-rank test was used for comparisons between groups. Hazard ratios for OS and PFS were obtained by univariate Cox regression models. We also classified response to platinum chemotherapy based on the interval between the dates of last platinum-based chemotherapy and disease progression as previously described (25). Response categories were: refractory - platinum-resistant (progression within 6 months); intermediate sensitivity $(6-<12$ months); platinum-sensitive $(\geq 12$ months); super responders were considered if high-grade (grade 2 and 3) and event free for $>60$ months. All tests were two-sided. SAS v.9.3 and JMP v.11 (SAS Institute Inc., Cary, NC, USA) were used for statistical analysis.

\section{Results}

Patient demographic and clinicopathological characteristics are shown in Table I. 54 (77.1\%) patients had stage III disease; 43 out of $52(82.7 \%)$ patients had serous while 8 out of 14 had endometrioid carcinomas and 1 out of 4 with mucinous carcinomas had bilateral ovarian manifestation. Out of 11 
Table I. Description of selected clinicopathological parameters.

\begin{tabular}{|c|c|c|}
\hline & Overall N & Median (min, max) \\
\hline \multirow[t]{2}{*}{ Age } & 70 & $59.5(31.0,80.0)$ \\
\hline & & $\mathrm{N}(\%)$ \\
\hline Age (median cut-off) & 70 & \\
\hline$>60$ & & $32(45.7)$ \\
\hline$\leq 60$ & & $38(54.3)$ \\
\hline Previous other cancer & 70 & \\
\hline No & & $67(95.7)$ \\
\hline Yes & & $3(4.3)$ \\
\hline Family history of cancer & 67 & \\
\hline No & & $34(50.7)$ \\
\hline Yes & & $33(49.3)$ \\
\hline Menopausal status & 70 & \\
\hline Postmenopausal & & $54(77.1)$ \\
\hline Premenopausal & & $16(22.9)$ \\
\hline Stage & 70 & \\
\hline IV & & $16(22.9)$ \\
\hline Non-IV & & $54(77.1)$ \\
\hline Laterality & 70 & \\
\hline Bilateral & & $52(74.3)$ \\
\hline Unilateral & & $18(25.7)$ \\
\hline Metastatic lymph nodes & 69 & \\
\hline No & & $51(73.9)$ \\
\hline Yes & & $18(26.1)$ \\
\hline Disease dissemination & 70 & \\
\hline Lower abdominal disease & & $49(70.0)$ \\
\hline Pelvic disease* ${ }^{*}$ & & $4(5.7)$ \\
\hline Upper abdominal disease & & $17(24.3)$ \\
\hline Histological type & 70 & \\
\hline Endometrioid & & $14(20.0)$ \\
\hline Mucinous & & $4(5.7)$ \\
\hline Serous & & $52(74.3)$ \\
\hline Grade & 70 & \\
\hline 1 & & $2(2.9)$ \\
\hline 2 & & $22(31.4)$ \\
\hline 3 & & $46(65.7)$ \\
\hline
\end{tabular}

*Ovaries and fallopian tubes.

germline mutation carriers, 8 had inherited a pathogenic variant of BRCA1 and one each of BRCA2, CHEK2 and BLM.

Morphological and biological characteristics in individual OVCA samples. Among all 294 whole tumor sections, the most common primary morphological subtype was PG $(\mathrm{n}=150,51.0 \%)$, followed by MT $(71,24.1 \%), \mathrm{SD}(48$, $16.3 \%)$ and IR $(15,5.1 \%)$. Heterogeneous tumors with secondary subtypes in the same section were identified in $67 / 294$ sections (22.8\%). The distribution of single and coexisting morphological subtypes is shown in Figure 2A. Intra-tissue heterogeneity significantly concerned SD and MT subtypes (Fisher's exact $p$-Values $<0.0001$ ). Out of 113 samples with MT, 63 (55.8\%) displayed a second subtype pattern; in 62 of these, MT coexisted with SD or PG. The IR subtype coexisted with a second subtype in $4 / 18$ tumors $(22.2 \%)$. SD and PG subtypes were never observed on the same tumor section. Subtypes showed site-of-origin specificity; PG prevailed in the ovaries, while SD and MT in implants (Figure 2B). However, these patterns concerned homogeneous tissues only; heterogeneous tissues were equally present in ovaries and implants.

sTIL density was assessed in 269 samples (median $=10 \%$; $\mathrm{IQR}=5-20 \%$; $\min -\max =0-90 \%$ ), was higher in implants than in ovaries (median $=10 \% v s .5 \%$, Wilcoxon rank-sum $p=0.002$ ), and was subtype-specific; it was positively associated with SD and inversely with PG (Figure 2C). In subtype-heterogeneous sections, sTIL density was biased towards the subtype occupying the larger area. Samples with the IR subtype were excluded from these comparisons. With respect to the site-oforigin, PG showed lower sTILs in ovaries (Wilcoxon rank-sum $p<0.001)$ and implants $(p=0.004)$ compared to non-PG; the MT subtype was associated with lower sTILs $(p=0.003)$ in implants.

As expected, OVCA malignant cells had a high Ki67 index ( 268 assessable samples, median $=50 \%$; IQR $=25-75 \%$; $\min -\max =10-100 \%)$ that did not differ with respect to sample origin. Ki67 was low in tumors with PG, and high in tumors with SD, compared to tumors without these subtypes (Figure 2D), although the latter did not reach statistical significance. The pattern of lower Ki67 in PG was only observed in the ovaries $(p=0.005)$ but not in implants; similarly, MT was associated with higher Ki67 $(p=0.016)$ in the ovaries only. Stromal Ki67 was assessed in 235 samples and was found uniformly low among tumors (median $=5 \%$, $\mathrm{IQR}=5-10 \%$, min- $\max =0-72 \%$ ). Higher stromal Ki67 was observed in the lymphocyte-rich IR and in SD samples (Figure 2E); this feature was retained for SD in both ovaries $(p=0.014)$ and implants $(p=0.034)$.

We also compared previously published sample genotypes (20) with morphological subtypes, sTILs and Ki67 in 251 samples, 214 of which (85.4\%) carried at least one pathogenic mutation. Samples with SD frequently had pathogenic mutations in any homologous recombination repair (HRR) gene, while TP53 mutations prevailed among samples with MT; intra-tissue heterogeneity was strongly associated with TP53 mutations and inversely with mutations in genes of the PI $3 \mathrm{~K}$ pathway (Figure 2F). TP53 mutations were also associated with higher Ki67 labeling (Wilcoxon rank-sum $p=0.024$ ).

Intra-patient heterogeneity (IPH) of morphological subtypes and STIL density. The distribution of morphological subtypes and sTIL values in matched samples per patient are shown in Figure 3A. The 67 samples with intra-tissue heterogeneity were distributed in 35 patients (50\% of the cohort). Apart from varying within one tissue section, tumor morphological subtypes varied extensively among samples obtained from different sites of the same patient. IPH was informative in 
A

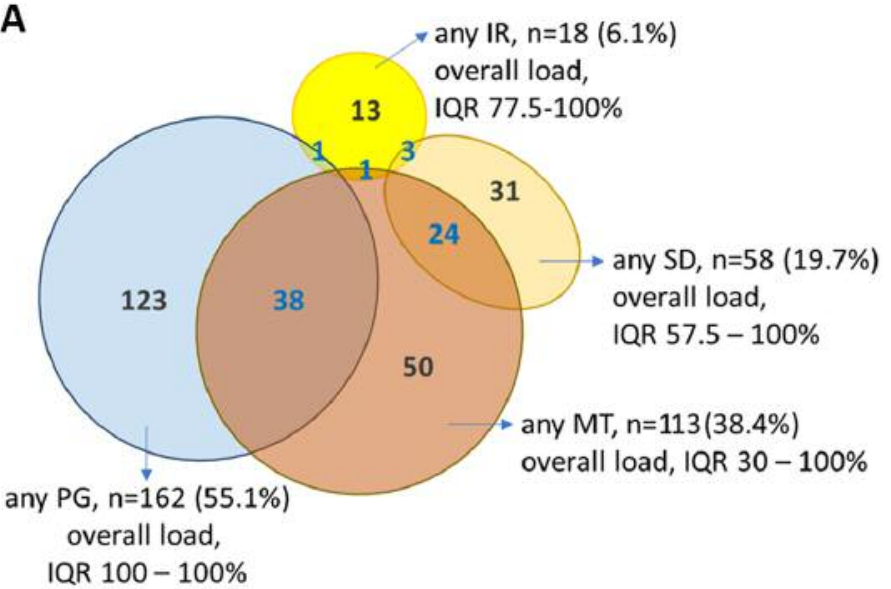

B

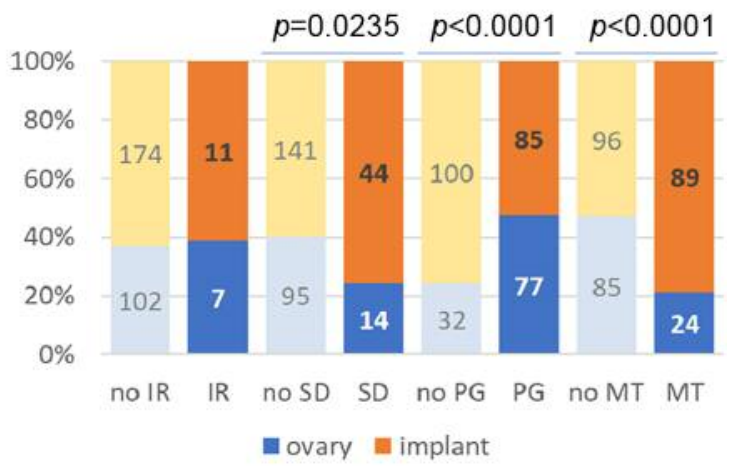

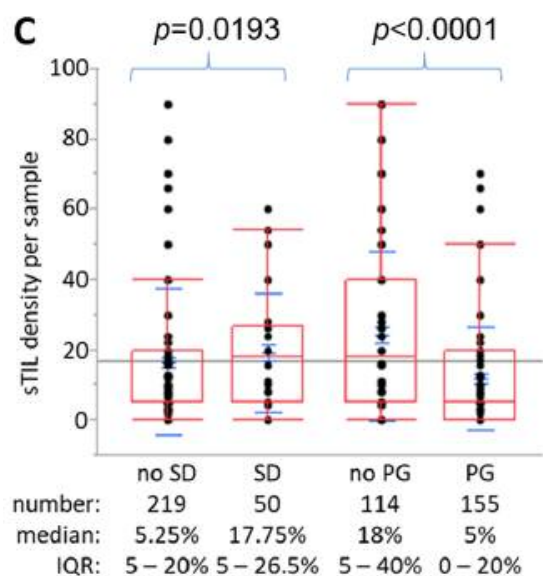

D $\quad p<0.0980(\mathrm{NS}) \quad p<0.0001$

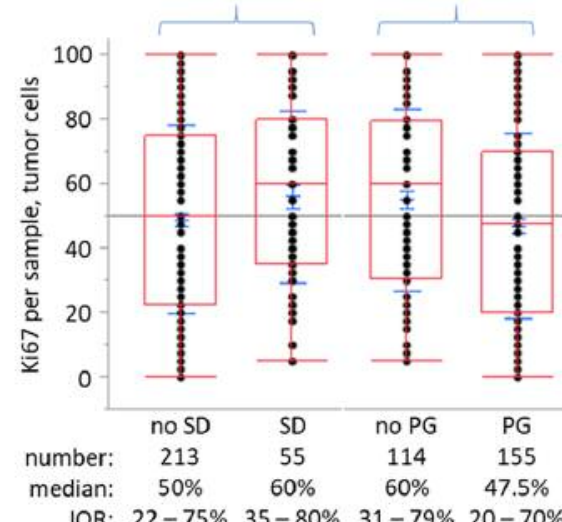

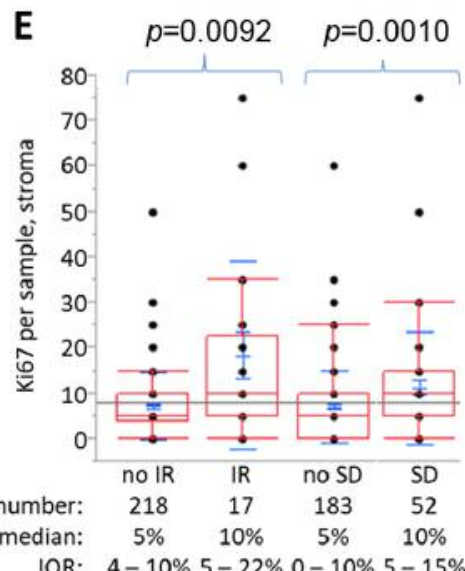

IQR: $4-10 \% 5-22 \% 0-10 \% 5-15 \%$
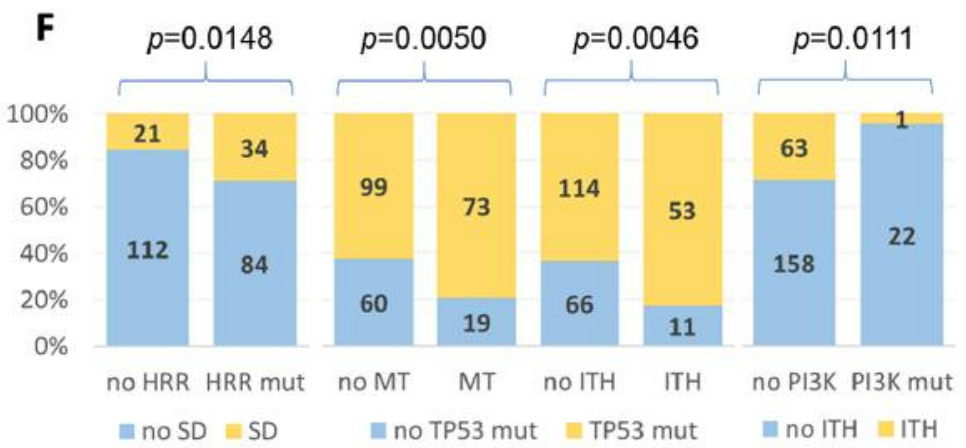

Figure 2. Morpho - biological characteristics of OVCA tissues. A. Morphological subtypes among 294 OVCA tumor samples from 70 patients. IR: immunoreactive; SD: solid; PG: papilloglandular; MT: mesenchymal transition; overall load: representation of each subtype among all samples; IQR: inter-quartile range. Diagram at approximate scale. Any IR, SD, PG, MT: the number and rate of samples with the particular subtype among all samples are addressed (samples with two subtypes are counted twice). Among the 67 tumor sections with intra-tissue heterogeneity, the median subtype load was $70 \%$ for papilloglandular (range $=10-95 \%$ ), 50\% for solid (10-90\%), 40\% for immunoreactive (10-80\%), and 30\% for mesenchymal transition (5-90\%). B. Associations between subtypes and site of origin, ovaries or implants. p-Values from Fisher's exact test. $C \& D$. Associations of solid and papilloglandular with stromal tumor-infiltrating lymphocyte (sTIL) density (in C) and with Ki67 labeling in malignant cells (in D). E. Stromal Ki67 labeling in lymphocyte-rich subtypes. C-E: p-Values from Wilcoxon rank-sum test. F. Significant associations between tissue histology and genomic characteristics per sample. ITH: intra-tissue heterogeneity. p-Values from Fisher's exact test. 
68 patients; two cases with only one homogeneous sample informative for morphological subtyping were excluded. IPH was observed in $48 / 68$ patients $(70.6 \%)$, including all patients with intra-tissue heterogeneity and 13 additional ones. The secondary subtype in sections from 33/35 patients with intra-tissue heterogeneity was present as the only subtype in sections from different sites in the same patient. Among the 20 patients without IPH, homogeneous PG was observed in 15, MT in 4 and SD in 1 patient. There was no case with homogeneous IR. Patients with IPH had various combinations of 2 or 3 morphological subtypes at various sites, but all 4 subtypes were never observed in the same patient. Intra-tissue heterogeneity and IPH were not related to the number of total samples or implants examined per patient or to disease laterality.

In line with morphological subtype IPH, sTIL density varied extensively among samples from the same patient (Figure 3A); a very high sTIL value in one implant, e.g. 70\%, did not preclude a very low sTIL value of $5 \%$ or even 0 in another. Max-TILs and average-TILs in the same patient were strongly correlated (Spearman's rho=0.9034). Unlike maxTILs or average-TILs, Euclidean distance (by definition) depended on the number of samples examined per patient (Wilcoxon rank-sum $p=0.014$ ). Max-TILs and average-TILs per patient depended on sTIL status in implants (Spearman's rho $=0.9743$ and 0.9624 , respectively) and less so in ovaries, while rho values between sTILs in ovaries and implants were even lower (Supplementary Table S1:

https://www.hecog.gr/images/stories/pdf/PAPERS_ONLINE/ Supplementary_Table_S1.pdf). Max-TILs and average-TILs positively correlated with IR-load in matched samples (Spearman's rho $>0.5$ ), while max-TILs in implants were inversely correlated with PG-load. A higher number of samples was associated with high SD-load $(p=0.016)$ but not with IR-, PG-, or MT-load.

Associations of morphological subtype and sTILs IPH with patient characteristics. IPH was more frequent in grade 3 than in grade 2 tumors (Fisher's $p=0.020$ ), was more frequent in stage IV $v s$. non-stage IV disease $(87.5 \%$ vs. $65.4 \%)$ although not of statistical significance (Fisher's exact test $p=0.121$ ), and was not associated with histology. The two patients with grade 1 tumors (one serous, one endometrioid) did not exhibit any intra-tissue or intra-patient heterogeneity, were of the PG subtype and had low sTILs $(0 \%$ and $5 \%)$.

Significant associations across standard clinicopathological parameters, morphological subtype load and the described sTIL parameters are shown in Table II. IR-load and MT-load were not associated with patient age, menopausal status at diagnosis, family history, disease laterality, stage and nodal status, histological type and grade, and germline status. SD-load was positively, and PG-load was inversely associated with nodal metastasis and higher grade. Because sTIL parameters were strongly intercorrelated, descriptive associations are presented for max-TILs. Higher max-TIL density was observed in patients with stage IV disease, upper abdominal dissemination, endometrioid histology, and grade 3 tumors. Similar results were obtained for max-TILs in implants, average-TILs in case and in implants, and for the Euclidean distance, when these parameters were examined either as continuous or as binary variables. Of note, max-TILs and average-TILs in ovaries did not yield any significant associations with clinicopathological parameters.

Morphological subtypes and sTILs on patient outcome. OS and PFS analyses were performed in 68 patients with highgrade tumors; all had received platinum-based chemotherapy. Among 67 patients with relevant available data, 22 (32.8\%) were non-responders (refractory), $14(20.9 \%)$ intermediate, $21(31.3 \%)$ platinum-sensitive, and 10 (14.9\%) were superresponders. Among all 4 patient classes, super responders had significantly higher max-TILs (Figure 3B) and averageTILs (Kruskal-Wallis $p=0.028$ ); the same parameters taken only from implants or ovaries were not related to treatment response. Euclidean distance was without effect.

Patients were followed for a median of 10.2 years $(95 \%$ $\mathrm{CI}=9.4-14.1)$. In this period, $57(83.8 \%)$ patients experienced disease progression and $54(79.4 \%)$ died; median PFS was 1.3 years $(95 \% \mathrm{CI}=0.9-1.9)$ and median OS 3.8 years $(95 \%$ $\mathrm{CI}=2.2-5.3)$. Univariate analysis results regarding the impact of clinicopathological and study parameters are shown in Table III. Out of all clinicopathological parameters, only patient age was statistically significant for OS. Higher Euclidean distance and max-sTILs (also shown in Figure 3C) were consistently associated with favorable PFS and OS, either as continuous or binary variables. Higher SD-load was associated with favorable PFS (Figure 3D) and reduced the risk for progression by $51 \%$ (Table III). IR- and PG-load were not associated with patient outcome, for IR most likely due to the small number of cases with this subtype. Although the hazard ratio for MT-load was in the expected direction (unfavorable), this finding did not reach statistical significance.

Germline data were available in only $60 \%$ of the patients including 11 carriers of pathogenic germline variants in HRR genes (truncating frameshifts and stopgains) (20). These numbers are too small for meaningful statistics but the data may be interesting for a case-per-case study. Among 5 BRCA1 carriers with tissue sequencing data available from multiple locations, the super responder to platinum-based chemotherapy and the long (>10 years) survivor had high max-TILs, high average-TILs and no IPH; in these patients, the germline variant was found at $>60 \%$ frequencies in tissues indicative of $\mathrm{LOH}$ and disrupted BRCA1 function. The remaining 4 patients were intermediate responders who died of disease; all of them had heterogeneous morphological subtypes and universally or partially monoallelic defects in tissues. 
A

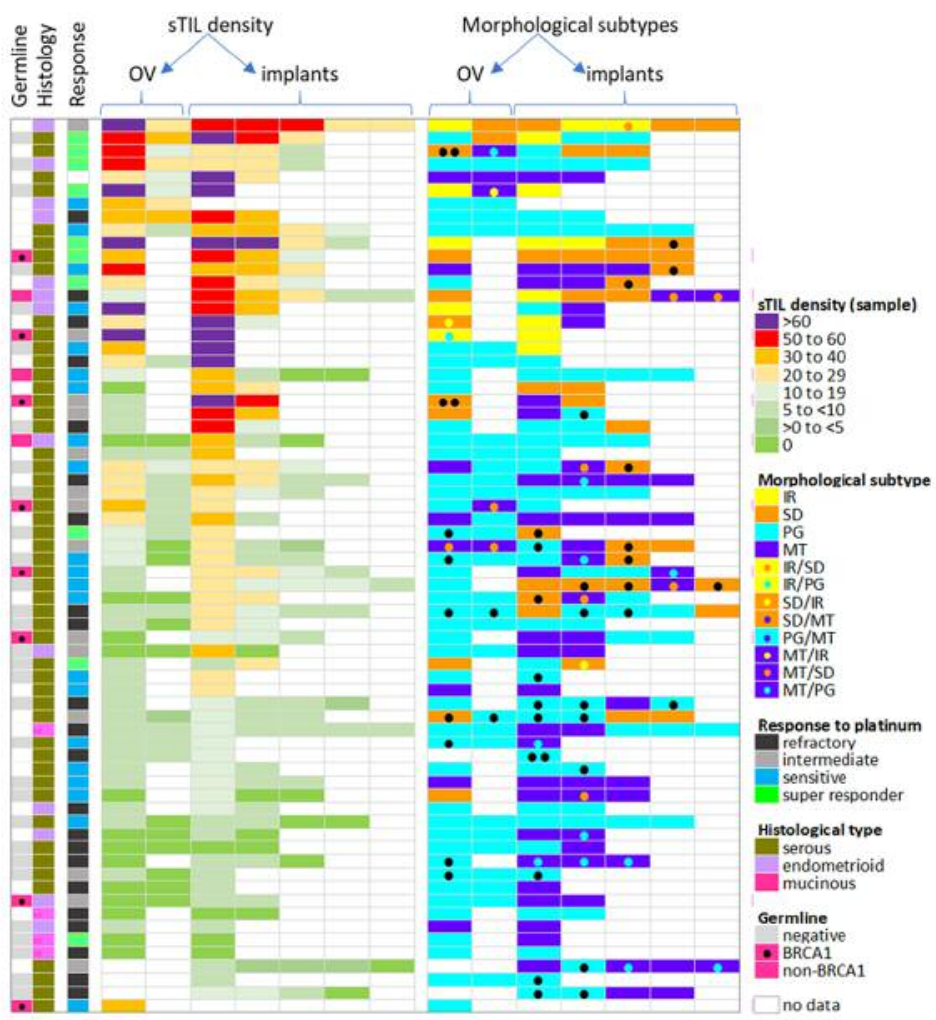

B

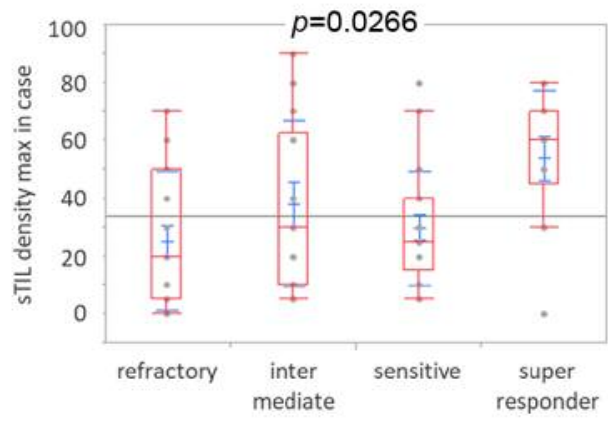

\section{C}

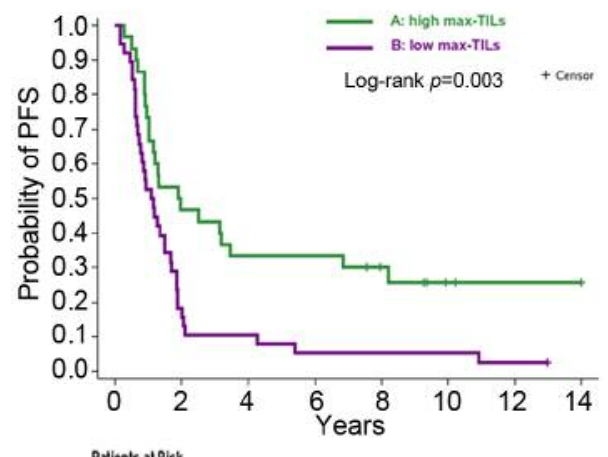

D

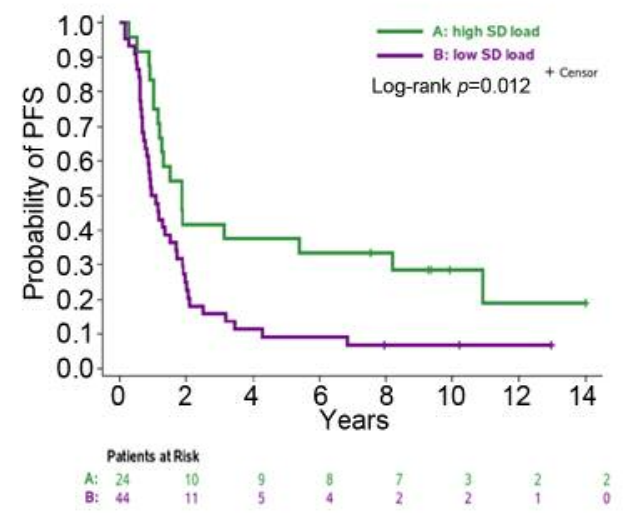

Figure 3. Morphological subtypes and stromal tumor-infiltrating lymphocyte (sTIL) density in 68 patients with high-grade OVCA. A. Map highlighting the observed histological heterogeneity (patient data in rows). Note the diversity of morphological subtypes and sTIL density among samples from the same patient. B. The group of patients with very favorable response to platinum (super responders) had significantly higher max-TIL values compared to all other categories. $C$ and D. Association of max-TILs per case and of the load of the solid subtype per case with PFS, respectively. 
Table II. Significant clinicopathological associations of morphological subtypes and sTIL density.

\begin{tabular}{|c|c|c|c|c|c|c|c|}
\hline & $\mathrm{N}$ & Mean & Std & Median & Min & $\operatorname{Max}$ & $p$-Value \\
\hline & \multicolumn{7}{|c|}{ SD load (range: 0 to 1 ) } \\
\hline Metastatic lymph nodes & & & & & & & 0.005 \\
\hline No & 51 & 0.09 & 0.18 & 0.00 & 0.00 & 0.67 & \\
\hline Yes & 18 & 0.26 & 0.29 & 0.24 & 0.00 & 1.00 & \\
\hline Grade & & & & & & & 0.010 \\
\hline 1 & 2 & 0.00 & 0.00 & 0.00 & 0.00 & 0.00 & \\
\hline 2 & 22 & 0.05 & 0.16 & 0.00 & 0.00 & 0.67 & \\
\hline \multirow[t]{2}{*}{3} & 46 & 0.18 & 0.24 & 0.00 & 0.00 & 1.00 & \\
\hline & \multicolumn{7}{|c|}{ PG load (range: 0 to 1 ) } \\
\hline Metastatic lymph nodes & & & & & & & 0.005 \\
\hline No & 51 & 0.62 & 0.35 & 0.64 & 0.00 & 1.00 & \\
\hline Yes & 18 & 0.32 & 0.34 & 0.25 & 0.00 & 1.00 & \\
\hline Grade & & & & & & & 0.026 \\
\hline 1 & 2 & 1.00 & 0.00 & 1.00 & 1.00 & 1.00 & \\
\hline 2 & 22 & 0.65 & 0.35 & 0.69 & 0.00 & 1.00 & \\
\hline \multirow[t]{2}{*}{3} & 46 & 0.47 & 0.36 & 0.49 & 0.00 & 1.00 & \\
\hline & \multicolumn{7}{|c|}{ Max-TILs in case (\%) } \\
\hline Stage & & & & & & & 0.043 \\
\hline IV & 16 & 44.38 & 24.21 & 50.00 & 10 & 80 & \\
\hline Non-IV & 54 & 30.19 & 25.29 & 20.00 & 0 & 90 & \\
\hline Disease dissemination & & & & & & & 0.024 \\
\hline Lower abdominal disease & 49 & 31.43 & 26.32 & 20.00 & 0 & 90 & \\
\hline Peritoneal disease & 4 & 11.25 & 13.15 & 7.50 & 0 & 30 & \\
\hline Upper abdominal disease & 17 & 44.41 & 21.20 & 50.00 & 5 & 80 & \\
\hline Histological type & & & & & & & 0.013 \\
\hline Endometrioid & 14 & 37.14 & 27.15 & 40.00 & 5 & 80 & \\
\hline Mucinous & 4 & 2.50 & 5.00 & 0.00 & 0 & 10 & \\
\hline Serous & 52 & 34.81 & 24.81 & 30.00 & 0 & 90 & \\
\hline Grade & & & & & & & 0.021 \\
\hline 1 & 2 & 2.50 & 3.54 & 2.50 & 0 & 5 & \\
\hline 2 & 22 & 27.95 & 27.85 & 20.00 & 0 & 90 & \\
\hline 3 & 46 & 37.39 & 23.85 & 30.00 & 5 & 80 & \\
\hline
\end{tabular}

Bold values indicate statistical significance.

\section{Discussion}

Routine pathology of OVCA captures significant lineagespecific biology and can predict tumor aggressive behavior, but does not account for anatomopathological heterogeneity or for tumor-host interactions (1). By examining tumor morphology and sTIL density in multiple matched primary and metastatic tumor sections this study uncovers extensive tumor and host immune response heterogeneity and demonstrates their biological and clinical impact. Importantly, information derived from ovarian samples alone did not reflect tumor histological composition in the implants and was not consistent in predicting patient outcomes.
Besides high-grade serous OVCA (HGSOC), the present cohort included a limited number of endometrioid and mucinous cancers. Thus, even though the herein described subtypes or IPH were not associated with WHO histological types, their incidence is cohort specific and not directly comparable to previous reports on larger series of exclusively HGSOC. Our findings on heterogeneous tumor growth patterns in OVCA contradict previous histological studies in which tissue samples were assigned with one morphological type at a time $(18,23)$. However, it is not unusual to encounter more than one morphological pattern on routine sections covering a surface of $>1 \mathrm{~cm}^{\wedge} 2$. Here, we did not classify tumors as MT using the previously suggested $10 \%$ cut-off per 
Table III. Hazard ratios and 95\% confidence intervals with respect to PFS and OS for morphological subtypes and sTILs*.

\begin{tabular}{|c|c|c|c|c|c|c|}
\hline & \multicolumn{3}{|c|}{ PFS } & \multicolumn{3}{|c|}{ OS } \\
\hline & Event/Total & $\begin{array}{l}\text { Hazard ratio } \\
(95 \% \mathrm{CI})^{\text {Cox }}\end{array}$ & $p$-Value & Event/Total & $\begin{array}{l}\text { Hazard ratio } \\
(95 \% \mathrm{CI})^{\mathrm{Cox}}\end{array}$ & $p$-Value \\
\hline \multicolumn{7}{|l|}{ sTILs Euclidean distance per case* } \\
\hline High & $25 / 33$ & $0.44(0.26-0.76)$ & 0.003 & $22 / 33$ & $0.45(0.26-0.80)$ & 0.006 \\
\hline Low & $31 / 32$ & Reference & -- & $29 / 32$ & Reference & -- \\
\hline \multicolumn{7}{|l|}{ Max-TILs in case* } \\
\hline High & $22 / 30$ & $0.44(0.26-0.76)$ & 0.003 & $19 / 30$ & $0.44(0.25-0.77)$ & 0.004 \\
\hline Low & $37 / 38$ & Reference & -- & $35 / 38$ & Reference & -- \\
\hline \multicolumn{7}{|l|}{ Max-TILs in ovaries* } \\
\hline High & $27 / 32$ & $0.69(0.41-1.17)$ & 0.167 & $24 / 32$ & $0.61(0.35-1.06)$ & 0.08 \\
\hline Low & $29 / 33$ & Reference & -- & $27 / 33$ & Reference & -- \\
\hline \multicolumn{7}{|l|}{ Max-TILs in implants* } \\
\hline High & $26 / 32$ & $0.58(0.34-0.99)$ & 0.044 & $23 / 32$ & $0.58(0.33-1.01)$ & 0.053 \\
\hline Low & $31 / 34$ & Reference & -- & $29 / 34$ & Reference & -- \\
\hline \multicolumn{7}{|l|}{ IR-load* } \\
\hline High & $8 / 10$ & $0.60(0.28-1.27)$ & 0.18 & $6 / 10$ & $0.44(0.19-1.03)$ & 0.057 \\
\hline Low & $51 / 58$ & Reference & -- & $48 / 58$ & Reference & -- \\
\hline \multicolumn{7}{|l|}{ MT-load* } \\
\hline High & $29 / 33$ & $1.34(0.80-2.24)$ & 0.263 & $28 / 33$ & $1.54(0.90-2.64)$ & 0.119 \\
\hline Low & $30 / 35$ & Reference & -- & $26 / 35$ & Reference & -- \\
\hline \multicolumn{7}{|l|}{ PG-load* } \\
\hline High & $31 / 33$ & $1.45(0.86-2.44)$ & 0.161 & $28 / 33$ & $1.33(0.78-2.27)$ & 0.293 \\
\hline Low & $28 / 35$ & Reference & -- & $26 / 35$ & Reference & -- \\
\hline \multicolumn{7}{|l|}{ SD-load* } \\
\hline High & $18 / 24$ & $0.49(0.28-0.87)$ & 0.014 & $17 / 24$ & $0.58(0.33-1.03)$ & 0.065 \\
\hline Low & $41 / 44$ & Reference & -- & $37 / 44$ & Reference & -- \\
\hline sTILs Euclidean distance per case $\mathrm{e}^{\wedge, @}$ & & $0.90(0.82-0.98)$ & 0.015 & & $0.89(0.81-0.98)$ & 0.012 \\
\hline Max-TILs in case $\mathrm{e}^{\wedge} @$ & & $0.86(0.76-0.96)$ & 0.007 & & $0.86(0.77-0.96)$ & 0.007 \\
\hline Max-TILs in ovaries ${ }^{\wedge, @ ~}$ & & $0.87(0.77-0.99)$ & 0.031 & & $0.84(0.73-0.96)$ & 0.013 \\
\hline Max-TILs in implants ${ }^{\wedge, @ ~}$ & & $0.90(0.80-1.00)$ & 0.058 & & $0.89(0.79-1.00)$ & 0.052 \\
\hline IR-load^ & & $0.45(0.09-2.23)$ & 0.327 & & $0.26(0.04-1.72)$ & 0.163 \\
\hline MT-load^ & & $1.55(0.66-3.63)$ & 0.314 & & $1.91(0.79-4.62)$ & 0.151 \\
\hline PG-load^ & & $1.58(0.79-3.19)$ & 0.198 & & $1.49(0.72-3.10)$ & 0.284 \\
\hline SD-load^ & & $0.22(0.06-0.85)$ & 0.028 & & $0.25(0.06-0.98)$ & 0.047 \\
\hline Age\#,^ & & $1.02(0.99-1.04)$ & 0.178 & & $1.02(1.00-1.05)$ & 0.07 \\
\hline \multicolumn{7}{|l|}{ Age $^{\#}$} \\
\hline$>60$ & $30 / 32$ & $1.52(0.91-2.54)$ & 0.111 & $29 / 32$ & $1.76(1.03-3.02)$ & 0.039 \\
\hline$\leq 60$ & $29 / 36$ & Reference & -- & $25 / 36$ & Reference & -- \\
\hline
\end{tabular}

*Median as a cut-off for high/low; ^continuous variables; @10\% increments; ${ }^{*}$ patient age was added to the table, since it was the only clinicopathological parameter associated with outcome (OS). Bold values indicate statistical significance.

section (23); instead, we evaluated the load of MT and every subtype per section and per patient. With this approach, our results are in line with molecular subtype heterogeneity $(7,9)$.

Molecular and morphological evidence suggest that heterogeneity could be explained by the interaction of tumor cell genomes and functional properties with the host mesenchyme at dissemination sites $(7,11,12,22,26-28)$. This view is further supported by the elimination of mesenchymal and immunoreactive subtypes in patientderived xenografts growing in a mouse stromal environment (11) and by the pan-cancer subtypes among 32 different cancer types (29). The amount of stroma in a tumor, i.e., tumor purity, contributes to the heterogeneity and low reproducibility of molecular subtypes (12). Interestingly, both the mesenchymal subtype and infiltrative or desmoplastic growth patterns are more frequently observed in OVCA implants $(9,10,30)$, while the levels of mesenchymal and immune response gene transcripts are elevated upon metastasis (11). The described predominance of MT in heterogeneous sections and its higher incidence in implants is compatible with stromal dependencies of molecular subtypes in OVCA classification. These results 
collectively suggest that assessing carcinoma cells and stromal components separately may be of value for tissue profiling and that $H \& E$ constitutes the simplest and most inexpensive way of achieving this in daily practice.

Molecular signatures reflect variations in tumor purity; tumors of lower purity are usually assigned to poorer prognostic groups. Worse outcomes may arise from the lower resectability of low-purity tumors that decreases the likelihood of achieving a complete treatment response (26, 31 ), while stroma-related platinum-chemoresistance has also been described (32). We were not able to explore such hypotheses in our data; it is possible, however, that stromal content and the herein described favorable SD subtype are both manifestations of tumor purity. High-purity tumors with an extremely dense "epithelial" component can appear as expansile "solid" proliferations, whereas low-purity tumors are less dense and may contain variable amounts of intervening stroma, creating the classical impression of destructive invasion on H\&E slides. In our series, SD tumors were high-grade with increased proliferation, more sTILs, and a propensity for mutations in HRR genes. This constellation of features coupled with the observed survival benefit for these patients is reminiscent of previous genotype/phenotype associations that confer increased platinum sensitivity in HGSOC $(33,34)$. In our classification, SD appeared closer to IR tumors, similarly to medullary-like and medullary breast carcinomas (35). In SD tumors, increased vulnerability to platinum-treatment may be due to increased replication (36), aided by HRR defects, with the synergistic effect of sTILs. The identification of the SD subtype seems of clinical relevance in OVCA.

Genotype/phenotype associations with respect to the previously described histologic patterns in BRCA $1 / 2$ carriers (33) were not possible in this study due to the limited number of respective carriers. In line with the previously published genotype heterogeneity for these patients (20), intra-patient morphological heterogeneity and response to treatment were linked to the status of the inherited variant in tumors, i.e., $\mathrm{LOH}$ (BRCA1 disruption) or monoallelic defect or potential elimination of the inherited variant or combinations of the above. Other than previously suggested (37), information on the germline variant allele frequency in tumors has not yet been globally integrated in laboratory reports. Changing this will bring the scientific and clinical community towards a more pragmatic patient assessment in the context of precision oncology.

In addition to morphological variability, our study also provides insights on intra-patient differences of sTIL density. Even though an increased number of sTILs in one site appeared to correlate with higher probability of elevated stromal immune response across sites, it was not uncommon that very high and very low sTIL densities coexisted in the same patient. This type of heterogeneity is described in the literature $(21,28,38)$ and seems worth assessing for predicting prognosis (38), which is indicated here as well.

Surrogates of molecular profiles are common in the practice of pathology because slide reading provides interpretable context and staining is cheaper than genomic and transcriptomic analyses (39-41). Further development of the proposed morphological surrogates for OVCA (23, 33 ), including the modifications described herein, may aid in predicting treatment benefit. To this end, detailed assessment of all available histological material from HGOVCA extending beyond the routinely practiced "one representative sample" per patient may be necessary. With the number of pathologists predicted to decrease worldwide $(42,43)$, proposing that histological subtypes and sTILs are to be assessed on each available tumor block from cytoreductive surgical material may appear unrealistic. An additional caveat is that morphological subtypes are only moderately reproducible (9). Examining the validity of morphological surrogates in pathology may be aided by advanced algorithms with deep learning capabilities in order to robustly map molecular traits or morphological patterns onto outcomes within fully automated workflows (44).

Limitations of our study are the absence of data on debulking status, the inclusion of a small number of nonHGSOC tumors, the small number of cases and the use of slightly modified criteria for the definition of subtypes. The main strengths are the detailed assessment of morphological subtypes within histological sections and across anatomical sites and the simultaneous study of sTILs, which is to our knowledge the most extensive investigation of OVCA heterogeneity in this context.

\section{Conclusion}

We have shown that PG, MT, SD and IR histological subtypes, previously proposed as surrogates of the molecular subtypes of HGSOC, may coexist within the same tumor histological slide in varying proportions and very frequently co-occur within different ovarian primaries and implants of the same patient. When considering the total burden of the subtypes in all anatomical sites containing tumor implants, morphological heterogeneity was clinically significant, with SD predicting a favorable outcome. Furthermore, we observed a wide range of sTIL densities across samples from the same patient and demonstrated the importance of assessing sTILs in all samples from a surgical specimen for predicting the outcome. Finally, we report an interesting association between the SD subtype, sTILs and features suggestive of platinum sensitivity, which may warrant further investigation. Heterogeneity of HG-OVCA may limit the ability of pre-operative biopsies to decipher whether the total tumor is more amenable to certain treatment modalities. 


\section{Supplementary Material}

Available at:

https://www.hecog.gr/images/stories/pdf/PAPERS_ONLINE/Suppl

ementary_Table_S1.pdf

\section{Conflicts of Interest}

Dr. Lakis: Employee of NEO New Oncology GmbH and Definiens GmbH/AstraZeneca. Consultant of BioTech AG. Dr. Fountzilas: Advisory Board of Pfizer, Sanofi and Roche. Honoraria from AstraZeneca. Stock ownership of ARIAD and GENPREX. The rest of the Authors declare no conflicts of interest.

\section{Authors' Contributions}

Conceptualization SL, VK, GF. Methodology SL, VK. Validation: GAK. Formal analysis: GAK, VK. Investigation SL, SC, VK, GF. Resources: GF, IE, AP, VK. Data curation: SL, VK, GAK. Writing - Original Draft: SL, VK. Writing - Review \& editing: all Authors. Visualization: VK, SL. Supervision: VK, PZ, GF. Project administration: GF, VK. Funding Acquisition: GF, VK.

\section{Acknowledgements}

The Authors wish to thank Mrs. Emily Daskalaki and Mrs. Eleni Sgouramalli for technical assistance and Mrs. Maria Moschoni for secretarial support.

\section{Funding Information}

This translational study was supported by an AstraZeneca research grant and by an internal Hellenic Cooperative Oncology Group (HeCOG) translational research grant. The funders played no role in study design, data collection and analysis, decision to publish, or preparation of the manuscript.

\section{References}

1 Kurman RJ, Carcangiu ML, Herrington CS and Young RH: Who classification of tumours of female reproductive organs. 4th edn. IARC publications: Lyon, 2014.

2 Meinhold-Heerlein I, Fotopoulou C, Harter P, Kurzeder C, Mustea A, Wimberger P, Hauptmann S and Sehouli J: The new who classification of ovarian, fallopian tube, and primary peritoneal cancer and its clinical implications. Arch Gynecol Obstet 293(4): 695-700, 2016. PMID: 26894303. DOI: 10.1007/s00404-016-4035-8

3 Weidle UH, Birzele F, Kollmorgen $G$ and Rueger R: Mechanisms and targets involved in dissemination of ovarian cancer. Cancer Genomics Proteomics 13(6): 407-423, 2016. PMID: 27807064. DOI: $10.21873 / \operatorname{cgp} .20004$

4 NCCN clinical practice guidelines in oncology (NCCN guidelines $\left.{ }^{\circledR}\right)$ : Ovarian cancer including fallopian tube cancer and primary peritoneal cancer: 2019. Available at: Https://www.NCCN.Org/professionals/physician_gls/pdf/ovarian.pdf

5 Gadducci A, Cosio S, Lissoni AA, Zizioli V, Adorni M, Ferrero AM, Landoni $F$ and Sartori E: Impact of bevacizumabcontaining primary treatment on outcome of recurrent ovarian cancer: An italian study. Anticancer Res 40(3): 1543-1550, 2020. PMID: 32132055. DOI: 10.21873/anticanres.14100

6 Siegel RL, Miller KD and Jemal A: Cancer statistics, 2019. CA Cancer J Clin 69(1): 7-34, 2019. PMID: 30620402. DOI: $10.3322 /$ caac. 21551

7 Verhaak RG, Tamayo P, Yang JY, Hubbard D, Zhang H, Creighton CJ, Fereday S, Lawrence M, Carter SL, Mermel CH, Kostic AD, Etemadmoghadam D, Saksena G, Cibulskis K, Duraisamy S, Levanon K, Sougnez C, Tsherniak A, Gomez S, Onofrio R, Gabriel S, Chin L, Zhang N, Spellman PT, Zhang Y, Akbani R, Hoadley KA, Kahn A, Kobel M, Huntsman D, Soslow RA, Defazio A, Birrer MJ, Gray JW, Weinstein JN, Bowtell DD, Drapkin R, Mesirov JP, Getz G, Levine DA, Meyerson M and Cancer Genome Atlas Research N: Prognostically relevant gene signatures of high-grade serous ovarian carcinoma. J Clin Invest 123(1): 517-525, 2013. PMID: 23257362. DOI: 10.1172/JCI65833

8 Leong HS, Galletta L, Etemadmoghadam D, George J, Australian Ovarian Cancer S, Kobel M, Ramus SJ and Bowtell D: Efficient molecular subtype classification of high-grade serous ovarian cancer. J Pathol 236(3): 272-277, 2015. PMID: 25810134. DOI: $10.1002 /$ path.4536

9 Tan TZ, Heong V, Ye J, Lim D, Low J, Choolani M, Scott C, Tan DSP and Huang RY: Decoding transcriptomic intra-tumour heterogeneity to guide personalised medicine in ovarian cancer. J Pathol 247(3): 305-319, 2019. PMID: 30374975. DOI: 10.1002/path.5191

10 Tothill RW, Tinker AV, George J, Brown R, Fox SB, Lade S, Johnson DS, Trivett MK, Etemadmoghadam D, Locandro B, Traficante N, Fereday S, Hung JA, Chiew YE, Haviv I, Australian Ovarian Cancer Study G, Gertig D, DeFazio A and Bowtell DD: Novel molecular subtypes of serous and endometrioid ovarian cancer linked to clinical outcome. Clin Cancer Res 14(16): 5198-5208, 2008. PMID: 18698038. DOI: 10.1158/1078-0432.CCR-08-0196

11 Zhang S, Jing Y, Zhang M, Zhang Z, Ma P, Peng H, Shi K, Gao WQ and Zhuang G: Stroma-associated master regulators of molecular subtypes predict patient prognosis in ovarian cancer. Sci Rep 5: 16066, 2015. PMID: 26530441. DOI: 10.1038/srep16066

12 Chen GM, Kannan L, Geistlinger L, Kofia V, Safikhani Z, Gendoo DMA, Parmigiani G, Birrer M, Haibe-Kains B and Waldron L: Consensus on molecular subtypes of high-grade serous ovarian carcinoma. Clin Cancer Res 24(20): 5037-5047, 2018. PMID: 30084834. DOI: 10.1158/1078-0432.CCR-18-0784

13 Konecny GE, Wang C, Hamidi H, Winterhoff B, Kalli KR, Dering J, Ginther C, Chen HW, Dowdy S, Cliby W, Gostout B, Podratz KC, Keeney G, Wang HJ, Hartmann LC, Slamon DJ and Goode EL: Prognostic and therapeutic relevance of molecular subtypes in high-grade serous ovarian cancer. J Natl Cancer Inst 106(10), 2014. PMID: 25269487. DOI: 10.1093/jnci/dju249

14 Parker LP, Taylor DD, Kesterson S and Gercel-Taylor C: Gene expression profiling in response to estradiol and genistein in ovarian cancer cells. Cancer Genomics Proteomics 6(3): 189194, 2009. PMID: 19487548.

15 Greaves $M$ and Maley CC: Clonal evolution in cancer. Nature 481(7381): 306-313, 2012. PMID: 22258609. DOI: 10.1038/nature 10762

16 McPherson AW, Chan FC and Shah SP: Observing clonal dynamics across spatiotemporal axes: A prelude to quantitative fitness models for cancer. Cold Spring Harb Perspect Med 8(2), 2018. PMID: 28630229. DOI: 10.1101/cshperspect.a029603 
17 Bashashati A, Ha G, Tone A, Ding J, Prentice LM, Roth A, Rosner J, Shumansky K, Kalloger S, Senz J, Yang W, McConechy M, Melnyk N, Anglesio M, Luk MT, Tse K, Zeng T, Moore R, Zhao Y, Marra MA, Gilks B, Yip S, Huntsman DG, McAlpine JN and Shah SP: Distinct evolutionary trajectories of primary high-grade serous ovarian cancers revealed through spatial mutational profiling. J Pathol 231(1): 21-34, 2013. PMID: 23780408. DOI: 10.1002/path.4230

18 Schwarz RF, Ng CK, Cooke SL, Newman S, Temple J, Piskorz AM, Gale D, Sayal K, Murtaza M, Baldwin PJ, Rosenfeld N, Earl HM, Sala E, Jimenez-Linan M, Parkinson CA, Markowetz F and Brenton JD: Spatial and temporal heterogeneity in high-grade serous ovarian cancer: A phylogenetic analysis. PLoS Med 12(2): e1001789, 2015. PMID: 25710373. DOI: 10.1371/journal.pmed.1001789

19 McPherson A, Roth A, Laks E, Masud T, Bashashati A, Zhang AW, Ha G, Biele J, Yap D, Wan A, Prentice LM, Khattra J, Smith MA, Nielsen CB, Mullaly SC, Kalloger S, Karnezis A, Shumansky K, Siu C, Rosner J, Chan HL, Ho J, Melnyk N, Senz J, Yang W, Moore R, Mungall AJ, Marra MA, Bouchard-Cote A, Gilks CB, Huntsman DG, McAlpine JN, Aparicio S and Shah SP: Divergent modes of clonal spread and intraperitoneal mixing in high-grade serous ovarian cancer. Nat Genet 48(7): 758-767, 2016. PMID: 27182968. DOI: $10.1038 / \mathrm{ng} .3573$

20 Kotoula V, Lakis S, Tikas I, Giannoulatou E, Lazaridis G, Papadopoulou K, Manoussou K, Efstratiou I, Papanikolaou A, Fostira F, Vlachos I, Tarlatzis B and Fountzilas G: Pathogenic BRCA1 mutations may be necessary but not sufficient for tissue genomic heterogeneity: Deep sequencing data from ovarian cancer patients. Gynecol Oncol 152(2): 375-386, 2019. PMID: 30446274. DOI: 10.1016/j.ygyno.2018.11.016

21 Jimenez-Sanchez A, Memon D, Pourpe S, Veeraraghavan H, Li Y, Vargas HA, Gill MB, Park KJ, Zivanovic O, Konner J, Ricca J, Zamarin D, Walther T, Aghajanian C, Wolchok JD, Sala E, Merghoub T, Snyder A and Miller ML: Heterogeneous tumorimmune microenvironments among differentially growing metastases in an ovarian cancer patient. Cell 170(5): 927-938 e920, 2017. PMID: 28841418. DOI: 10.1016/j.cell.2017.07.025

22 Zhang AW, McPherson A, Milne K, Kroeger DR, Hamilton PT, Miranda A, Funnell T, Little N, de Souza CPE, Laan S, LeDoux S, Cochrane DR, Lim JLP, Yang W, Roth A, Smith MA, Ho J, Tse K, Zeng T, Shlafman I, Mayo MR, Moore R, Failmezger H, Heindl A, Wang YK, Bashashati A, Grewal DS, Brown SD, Lai D, Wan ANC, Nielsen CB, Huebner C, Tessier-Cloutier B, Anglesio MS, Bouchard-Cote A, Yuan Y, Wasserman WW, Gilks CB, Karnezis AN, Aparicio S, McAlpine JN, Huntsman DG, Holt RA, Nelson $\mathrm{BH}$ and Shah SP: Interfaces of malignant and immunologic clonal dynamics in ovarian cancer. Cell 173(7): 1755-1769 e1722, 2018. PMID: 29754820. DOI: 10.1016/j.cell.2018.03.073

23 Murakami R, Matsumura N, Mandai M, Yoshihara K, Tanabe H, Nakai H, Yamanoi K, Abiko K, Yoshioka Y, Hamanishi J, Yamaguchi K, Baba T, Koshiyama M, Enomoto T, Okamoto A, Murphy SK, Mori S, Mikami Y, Minamiguchi S and Konishi I: Establishment of a novel histopathological classification of highgrade serous ovarian carcinoma correlated with prognostically distinct gene expression subtypes. Am J Pathol 186(5): 1103-1113, 2016. PMID: 26993207. DOI: 10.1016/j.ajpath.2015.12.029

24 Salgado R, Denkert C, Demaria S, Sirtaine N, Klauschen F, Pruneri G, Wienert S, Van den Eynden G, Baehner FL, PenaultLlorca F, Perez EA, Thompson EA, Symmans WF, Richardson AL, Brock J, Criscitiello C, Bailey H, Ignatiadis M, Floris G,
Sparano J, Kos Z, Nielsen T, Rimm DL, Allison KH, Reis-Filho JS, Loibl S, Sotiriou C, Viale G, Badve S, Adams S, WillardGallo K, Loi $\mathrm{S}$ and International TWG: The evaluation of tumor-infiltrating lymphocytes (tils) in breast cancer: Recommendations by an international tils working group 2014. Ann Oncol 26(2): 259-271, 2015. PMID: 25214542. DOI: 10.1093/annonc/mdu450

25 Colombo PE, Fabbro M, Theillet C, Bibeau F, Rouanet P and Ray-Coquard I: Sensitivity and resistance to treatment in the primary management of epithelial ovarian cancer. Crit Rev Oncol Hematol 89(2): 207-216, 2014. PMID: 24071502. DOI: $10.1016 /$ j.critrevonc 2013.08 .017

26 Hunt AL, Bateman NW, Hood BL, Conrads KA, Zhou M, Litzi TJ, Oliver J, Mitchell D, Gist G, Blanton B, Odunsi K, Sood AK, Casablanca Y, Darcy KM, Shriver CD, Rao UNM, Maxwell GL and Conrads TP: Extensive intratumor proteogenomic heterogeneity revealed by multiregion sampling in a high-grade serous ovarian tumor specimen. BioRxiv, 2019. DOI: 10.1101/761155

27 Schwede M, Waldron L, Mok SC, Wei W, Basunia A, Merritt MA, Parmigiani G, Harrington D, Quackenbush J, Birrer M and Culhane AC: The impact of stroma on the discovery of molecular subtypes and prognostic gene signatures in serous ovarian cancer. BioRxiv, 2018. DOI: doi.org/10.1101/496406

28 Zhang Q, Wang C and Cliby WA: Cancer-associated stroma significantly contributes to the mesenchymal subtype signature of serous ovarian cancer. Gynecol Oncol 152(2): 368-374, 2019. PMID: 30448260. DOI: 10.1016/j.ygyno.2018.11.014

29 Chen F, Zhang Y, Gibbons DL, Deneen B, Kwiatkowski DJ, Ittmann $M$ and Creighton CJ: Pan-cancer molecular classes transcending tumor lineage across 32 cancer types, multiple data platforms, and over 10,000 cases. Clin Cancer Res 24(9): 21822193, 2018. PMID: 29440175. DOI: 10.1158/1078-0432.CCR$17-3378$

30 Ruba S, Doherty D and Stewart CJR: A detailed morphological and immunohistochemical comparison of primary endometrial and tubo-ovarian high-grade serous carcinomas and their corresponding omental metastases. Pathology, 2019. PMID: 31870502. DOI: 10.1016/j.pathol.2019.10.007

31 Torres D, Wang C, Kumar A, Bakkum-Gamez JN, Weaver AL, McGree ME, Konecny GE, Goode EL and Cliby WA: Factors that influence survival in high-grade serous ovarian cancer: A complex relationship between molecular subtype, disease dissemination, and operability. Gynecol Oncol 150(2): 227-232, 2018. PMID: 29925470. DOI: 10.1016/j.ygyno.2018.06.002

32 Lou E, Vogel RI, Hoostal S, Klein M, Linden MA, Teoh D and Geller MA: Tumor-stroma proportion as a predictive biomarker of resistance to platinum-based chemotherapy in patients with ovarian cancer. JAMA Oncol, 2019. PMID: 31152668. DOI: 10.1001/jamaoncol.2019.1943

33 Soslow RA, Han G, Park KJ, Garg K, Olvera N, Spriggs DR, Kauff ND and Levine DA: Morphologic patterns associated with brca1 and brca2 genotype in ovarian carcinoma. Mod Pathol 25(4): 625-636, 2012. PMID: 22193042. DOI: 10.1038/modpathol.2011.183

34 Hussein YR, Ducie JA, Arnold AG, Kauff ND, Vargas-Alvarez HA, Sala E, Levine DA and Soslow RA: Invasion patterns of metastatic extrauterine high-grade serous carcinoma with brca germline mutation and correlation with clinical outcomes. Am J Surg Pathol 40(3): 404-409, 2016. PMID: 26574845. DOI: 10.1097/PAS.0000000000000556 
35 Kleer CG: Carcinoma of the breast with medullary-like features: Diagnostic challenges and relationship with brca1 and ezh2 functions. Arch Pathol Lab Med 133(11): 1822-1825, 2009. PMID: 19886718. DOI: 10.1043/1543-2165-133.11.1822

36 Sun J, Bao S, Xu D, Zhang Y, Su J, Liu J, Hao D and Zhou M: Large-scale integrated analysis of ovarian cancer tumors and cell lines identifies an individualized gene expression signature for predicting response to platinum-based chemotherapy. Cell Death Dis 10(9): 661, 2019. PMID: 31506427. DOI: 10.1038/s41419019-1874-9

37 Capoluongo E, Ellison G, Lopez-Guerrero JA, Penault-Llorca F, Ligtenberg MJL, Banerjee S, Singer C, Friedman E, Markiefka B, Schirmacher P, Buttner R, van Asperen CJ, Ray-Coquard I, Endris V, Kamel-Reid S, Percival N, Bryce J, Rothlisberger B, Soong R and de Castro DG: Guidance statement on BRCA1/2 tumor testing in ovarian cancer patients. Semin Oncol 44(3): 187-197, 2017 PMID: 29248130. DOI: 10.1053/j.seminoncol.2017.08.004

38 Hwang C, Lee SJ, Lee JH, Kim KH, Suh DS, Kwon BS and Choi KU: Stromal tumor-infiltrating lymphocytes evaluated on h\&estained slides are an independent prognostic factor in epithelial ovarian cancer and ovarian serous carcinoma. Oncol Lett 17(5): 4557-4565, 2019. PMID: 30944645. DOI: 10.3892/ol.2019.10095

39 Vasconcelos I, Hussainzada A, Berger S, Fietze E, Linke J, Siedentopf $\mathrm{F}$ and Schoenegg W: The St. Gallen surrogate classification for breast cancer subtypes successfully predicts tumor presenting features, nodal involvement, recurrence patterns and disease free survival. Breast 29: 181-185, 2016 PMID: 27544822. DOI: 10.1016/j.brest.2016.07.016
40 Coudray N, Ocampo PS, Sakellaropoulos T, Narula N, Snuderl M, Fenyo D, Moreira AL, Razavian N and Tsirigos A: Classification and mutation prediction from non-small cell lung cancer histopathology images using deep learning. Nat Med 24(10): 15591567, 2018. PMID: 30224757. DOI: 10.1038/s41591-018-0177-5

41 Patil PD, Hobbs B and Pennell NA: The promise and challenges of deep learning models for automated histopathologic classification and mutation prediction in lung cancer. J Thorac Dis 11(2): 369372, 2019. PMID: 30962976. DOI: 10.21037/jtd.2018.12.55

42 RCPath. Meeting pathology demand. Available at: https://www.rcpath.org/uploads/assets/952a934d-2ec3-48c9a8e6e00fcdca700f/Meeting-Pathology-Demand-HistopathologyWorkforce-Census-2018.pdf

43 Metter DM, Colgan TJ, Leung ST, Timmons CF and Park JY: Trends in the US and canadian pathologist workforces from 2007 to 2017. JAMA Netw Open 2(5): e194337, 2019. PMID: 31150073. DOI: 10.1001/jamanetworkopen.2019.4337

44 Madabhushi A, Feldman MD and Leo P: Deep-learning approaches for gleason grading of prostate biopsies. Lancet Oncol, 2020. PMID: 31926804. DOI: 10.1016/S1470-2045(19)30793-4

Received June 12, 2020

Revised July 7, 2020

Accepted July 10, 2020 